\title{
Pengaruh Konseling terhadap Peningkatan Harga Diri Penderita Kusta
}

\section{Fahrur Rozi ${ }^{1}$, Yenni Hastuty ${ }^{2}$}

1. STIKES Bahrul Ulum Jombang

2. Universitas Nurul Jadid, Probolinggo

\section{Abstract :}

Leprosy is an infectious disease that causes very complex problems. The problem that is needed is not only from a medical point of view but also extends to social, economic problems for sufferers, thus allowing a change in the selfesteem of lepers. In this study, researchers used a Pre-trial research design (One-group Pre-testpost test Design). Taking respondents in this study used a consecutive sample technique in which the sample was patients in Sumber Glagah Leprosy Hospital, Pacet District, Mojokerto Regency, which corresponded to the inclusion and exclusion criteria of 30 respondents. The results showed that respondents' self-esteem before counseling was mostly moderate for 26 respondents (86.7\%), the self-esteem of respondents after counseling was mostly 20 respondents (66.7\%). To analyze the differences in influence on increasing selfesteem, a $T$ test was conducted using SPSS, obtained $a=0,000$, where $a<0.05$, which means $H 1$ was accepted or there was an increase in self-esteem at the Sumber Glagah Pacet Hospital Mojokerto. This involves the counseling factor itself that supports patient knowledge and is an application of the relationship between nurses and patients, so 
this counseling needs to be supported and programmed to improve patient effectiveness.

Keywords: Counseling, Self-Esteem, Leprosy

\section{Abstrak}

Penyakit kusta merupakan salah satu penyakit menular yang menimbulkan masalah yang sangat kompleks. Masalah yang dimaksud bukan hanya dari segi medis tetapi meluas sampai masalah sosial, ekonomi, budaya bagi para penderitanya, sehingga memungkinkan terjadinya perubahan pada harga diri penderita kusta ini. Dalam penelitian ini peneliti menggunakan desain penelitian Pra-eksperimen (One-group Pra-test-post test Design). Pengambilan responden dalam penelitian ini menggunakan tehnik Consecutive Sampling dimana sampelnya adalah penderita di Rumah Sakit Kusta Sumber Glagah Kecamatan Pacet Kabupaten Mojokerto yang sesuai dengan kriteria inklusi dan eksklusi sebanyak 30 responden. Hasil penelitian menunjukkan harga diri responden sebelum dilakukan konseling sebagian besar sedang 26 responden $(86,7 \%)$, harga diri responden setelah dilakukan konseling sebagian besar tinggi 20 responden (66,7\%). Untuk menganalisis adanya pengaruh konseling terhadap peningkatan harga diri maka dilakukan uji $\mathrm{T}$ dengan menggunakan SPSS, didapatkan $\mathrm{a}=0,000$, dimana $\mathrm{a}<0,05$ yang artinya $\mathrm{H} 1$ diterima atau 
ada pengaruh konseling terhadap peningkatan harga diri di Rumah Sakit kusta Sumber Glagah Pacet Mojokerto. Hal ini dipengaruhi oleh faktor konseling itu sendiri yang menunjang pengetahuan pasien kusta dan merupakan salah satu aplikasi hubungan terapiutik antara perawat dan pasien, maka konseling ini perlu dipertahankan dan dilakukan secara terprogram sehingga dampak psikologis pasien dapat teratasi.

Kata Kunci: Konseling, Harga Diri, Kusta 
Jurnal Keperawatan Profesional (JKP)

Volume 7, Nomor 1 Februar i 2019, Halaman xxx-xxx

p-ISSN: 2355-679X; e-ISSN: $\mathbf{x x x x - x x x x ~}$

Pendahuluan

Kusta adalah

penyakit yang masih banyak

dijumpai

pada

masyarakat

yang

ekonominya

menengah ke bawah.

Dengan pendidikan

tentang kesehatan

yang masih sangat

kurang dan ekonomi keluarga yang sangat rendah.

Permasalahan

penyakit kusta ini

bila dikaji secara

mendalam

merupakan masalah

yang

sangat

kompleks

dan

merupakan

permasalahan

kemanusiaan

seutuhnya. Para

penyandang dan

bekas penyandang

kusta identik dengan

golongan masyarakat miskin dan sebagian besar cacat fisik permanen. Anggota masyarakat masih mengalami ketakutan berinteraksi dengan penyandang kusta, itulah sebabnya mereka mengalami kesulitan ketika ingin bekerja secara mandiri. Pemerintah, lembaga sosial, maupun perorangan telah berupaya membantu mereka, misalnya menyediakan pelatihan atau dana untuk usaha, tetapi umumnya upaya ini berakhir dengan kegagalan, karena para penyandang kusta tidak leluasa mengembangkan usaha, karena kesulitan mendapatkan konsumen. Selama 
para penyandang kusta belum diterima masyarakat sama seperti warga lainnya, akan tetap sulit bagi mereka mendapatkan kehidupan sosial ekonomi yang baik di masyarakat.

Sedangkan dari segi ekonomi penderita kusta menimbulkan ketidak mampuan bekerja sehingga kebutuhan hidup menjadi tidak terpenuhi, apalagi mayoritas penderita penyakit ini dari kalangan ekonomi yang kurang mampu. Hal ini menyebabkan harga diri pasien kusta menjadi rendah dikarenakan masyarakat masih beranggapan bahwa penyakit kusta merupakan penyakit menular, tidak dapat diobati, penyakit keturunan, kutukan tuhan, najis, dan menyebabkan

kecacatan sehingga masyarakat tidak mau menerima penyandang kusta (Wardiati, 2009).

Pada klien kusta perubahan harga diri sangat mungkin terjadi jika ada stresor yang menyertai klien. Stresor tersebut adalah kecacatan yang di akibatkan karena adanya perubahan struktur tubuh, perubahan bentuk tubuh, perubahan fungsi, dan perubahan penampilan.

Seseorang dengan perubahan-

perubahan tersebut menyebabkan individu kehilangan peran dalam 
kehidupannya.

Hilangnya

peran

membuat individu

sering mengucilkan

diri, merasa tidak berguna

dan

berharga

sama

sekali, dan pada akhirnya

bisa

menimbulkan depresi

yang nantinya bisa

menyebabkan

penderita

kusta

mengalami gangguan

kejiwaan. Seorang

penderita kusta yang

mengalami kecacatan

secara pasti akan

dihadapkan kepada

suatu kehilangan

fungsi pengendalian

diri, kehilangan

peran,

dan

mengalami trauma

psikis. Dampak dari

kecacatan tersebut

sangatlah besar,

pada umumnya

penderita kusta

merasa rendah diri,

merasa tekanan batin, takut terhadap penyakitnya, malu dengan

kecacatannya, takut menghadapi keluarga dan masyarakat, karena sikap penerimaan

masyarakat yang kurang wajar, para penderita kusta enggan untuk berobat karena malu, apatis, tidak bisa mandiri sehingga membebani orang lain yang pada akhirnya mempengaruhi gangguan harga diri pada penderita (Parjo, 2007). Memperbaiki masalah harga diri pada penderita kusta perlu dilakukan konseling yang bertujuan untuk meningkatkan harga diri penderita kusta tersebut, agar tidak 
Fahrur Rozi: Konseling Kusta

$\begin{array}{lrlr}\text { timbul } & \text { perasaan } & \text { dan } & \text { lingkungan } \\ \text { minder, } & \text { perasaan } & \text { pengaruhnya sangat } \\ \text { malu, } & \text { takut } & \text { besar } & \text { terhadap } \\ \text { penyakitnya } & \text { tidak } & \text { proses peningkatan } \\ \text { bisa di sembuhkan, } & \text { harga diri penderita } \\ \text { merasa } & \text { tidak } & \text { kusta. }\end{array}$
berharga dan tidak berguna, dan tidak menimbulkan depresi pada penderita kusta, disamping itu keluarga dan masyarakat

lingkungan disekitar tempat tinggal penderita kusta perlu untuk diberikan informasi yang adekuat tentang penyakit kusta agar mereka bisa menerima penderita kusta dan tidak lagi mengucilkannya, hal ini dapat menunjang harga diri penderita kusta saat berada dalam lingkungan keluarga dan masyarakat, mengingat keluarga

\section{Metode}

Penelitian ini menggunakan Desain penelitian eksprimen adalah kegiatan percobaan (experiment), yang bertujuan untuk mengetahui suatu gejala atau pengaruh yang timbul, sebagai akibat dari adanya perlakuan tertentu, dengan jumlah 39 Orang, penelitian ini menggunakan teknik nonprobability sampling tepatnya Consecutive Sampling . Adapun kriteria dari sampel sangat membantu peneliti untuk mengurangi bias hasil penelitian, khususnya jika terhadap variabel (kontrol/pemicu) yang ternyata mempunyai 
Fahrur Rozi: Konseling Kusta

pengaruh terhadap

variabel yang kita teliti

Hasil Penelitian

1. Data Umum

a. Distribusi frekuensi karakteristik

responden

berdasarkan jenis kelamin

Tabel 1 Distribusi

berdasarkan jenis

kelamin

$\begin{array}{llll}\text { No } & \text { Jenis } & \text { responden }(40 \%) & \text { \% } \\ & \text { Kelamin } & \text { Data Khusus }\end{array}$

\begin{tabular}{ccccll}
\hline 1 & Laki-laki & 16 & $53^{\text {a. }}$. Harga & diri \\
2 & Perempuan & 14 & 47 & responden sebelum \\
\hline & Total & $\mathbf{3 0}$ & $\mathbf{1 0 0}$ & dilakukan &
\end{tabular}

Berdasarkan hasil

penelitian pada tabel $1 \mathrm{di}$ atas, didapatkan sebagian besar adalah laki-laki yaitu sebanyak 16 responden (53\%).

a. Karakteristik responden berdasarkan usia

Tabel 2 Distribusi berdasarkan usia

\begin{tabular}{cccc}
\hline $\mathrm{N}$ & Usia & $\mathrm{F}$ & $\%$ \\
$\mathrm{o}$ & & & \\
\hline 1 & $20-$ & 5 & 17
\end{tabular}

Tabel 3 Distribusi

Frekuensi Harga Diri Responden Sebelum Konseling Di Rumah Sakit Kusta Sumber Glagah Pacet Mojokerto.

\begin{tabular}{cccc}
\hline $\mathrm{N}$ & Kriteri & Pre & $(\%)$ \\
$\mathrm{o}$ & $\mathrm{a}$ & Tes & \\
& Harga & $\mathrm{t}$ & \\
& Diri & & \\
\hline 1 & Renda & 4 & 13,3 \\
& $\mathrm{~h}$ & & $\%$ \\
& Sedan & 26 & 86,7
\end{tabular}


Fahrur Rozi: Konseling Kusta

\begin{tabular}{|c|c|c|c|}
\hline 3 & $\begin{array}{c}\mathrm{g} \\
\text { tinggi }\end{array}$ & 0 & $\begin{array}{c}\% \\
0,0 \%\end{array}$ \\
\hline & Total & 30 & 100 \\
\hline & & & $\%$ \\
\hline
\end{tabular}

b. Tabulasi silang pre dan post test pengaruh konseling terhadap

peningkatan harga diri pasien kusta

Tabel 4 Tabulasi Silang Harga

Diri Responden Sebelum Dan Sesudah Diberikan Konseling Berdasarkan Jenis Kelamin Di Rumah Sakit Kusta Sumber Glagah Pacet Mojokerto

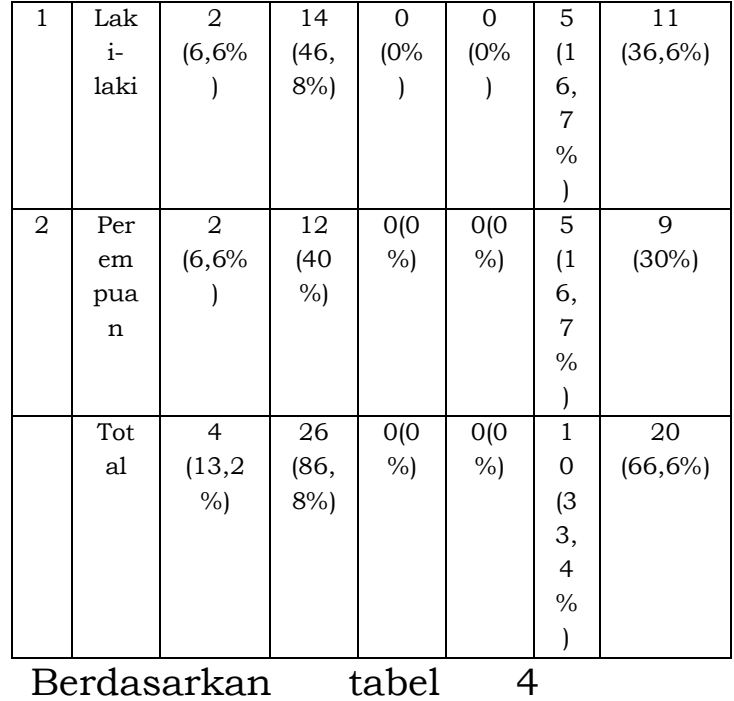

terlihat bahwa sebelum diberi konseling, dari 30 responden yang mempunyai harga diri sedang sebagian besar berjenis kelamin laki-laki sebanyak 14 responden $(46,8 \%), \quad$ sedangkan setelah diberi konseling, dari 30 responden yang mempunyai harga diri tinggi sebagian besar berjenis kelamin laki-laki sebanyak 11 responden

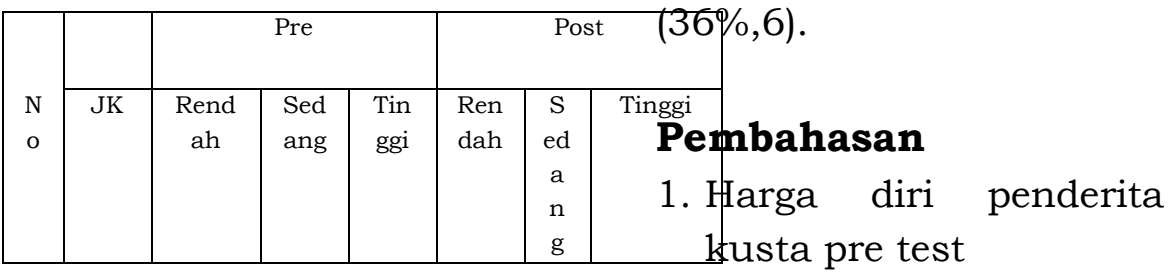


Fahrur Rozi: Konseling Kusta

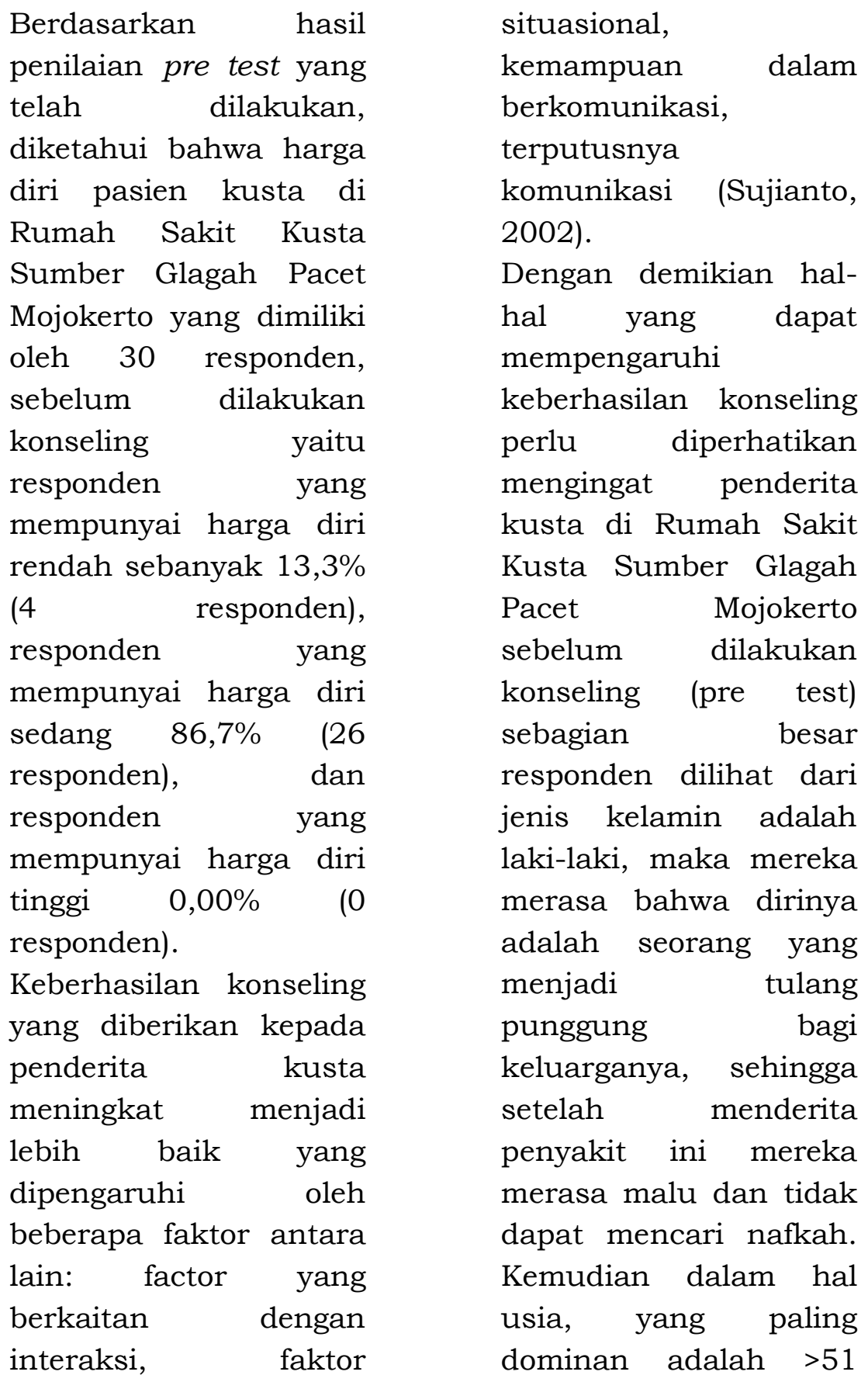


Fahrur Rozi: Konseling Kusta

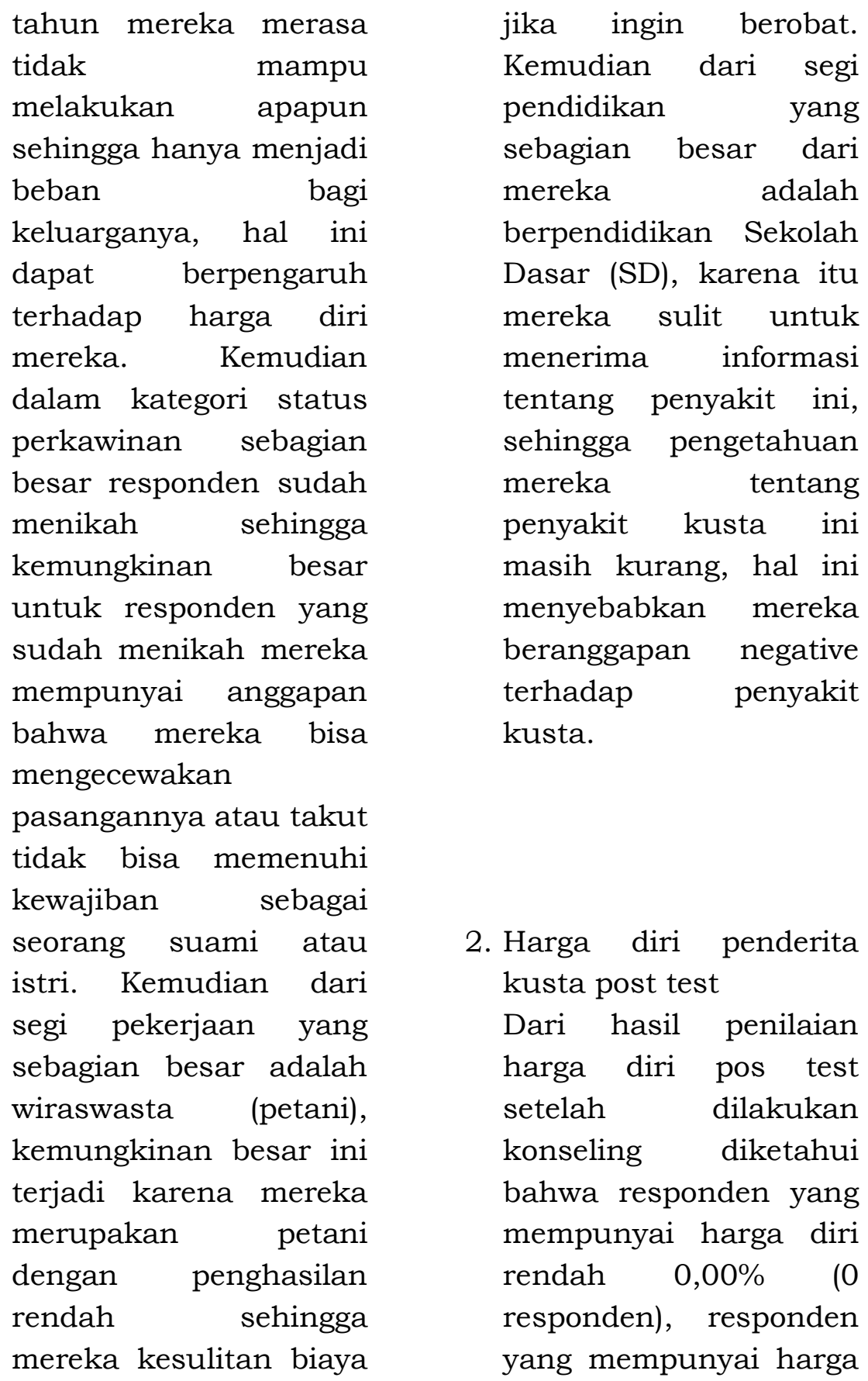




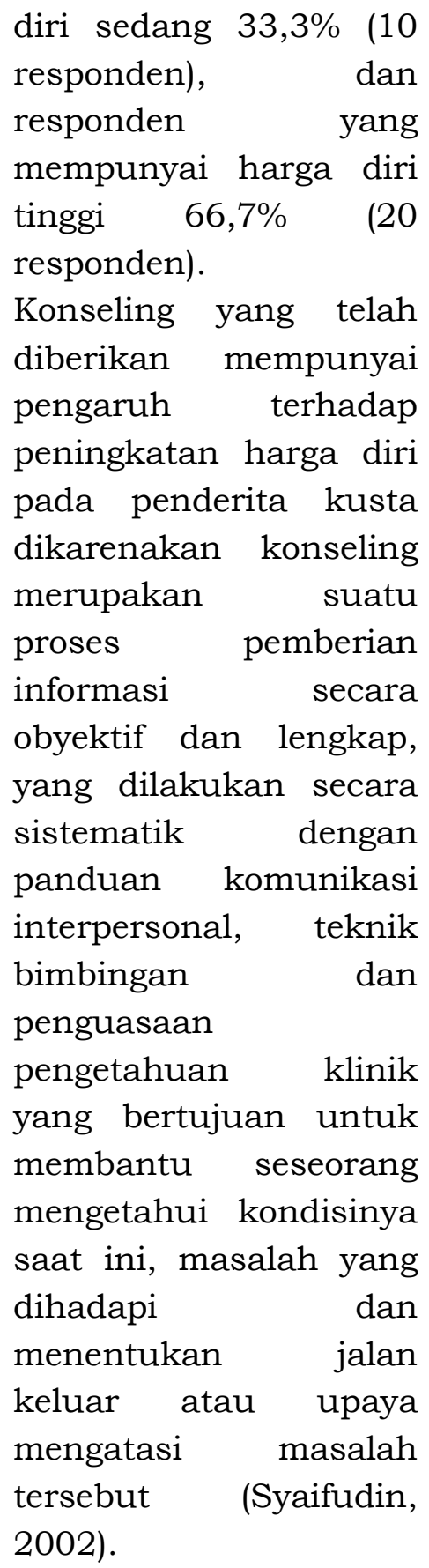

Berdasarkan fakta dan teori diatas, penderita kusta di Rumah Sakit Kusta Sumber Glagah Pacet Mojokerto kebanyakan harga dirinya relative meningkat setelah dilakukan konseling, kemungkinan

dikarenakan sebagian besar responden dilihat dari jenis kelamin adalah laki-laki, mereka merasa bahwa dirinya adalah seorang yang menjadi pemimpin yang bertanggung jawab atas keluarga. Kemudian dalam hal usia, yang paling dominan adalah $>51$ tahun dimana pada usia ini seseorang merasa akan lebih jika banyak beribadah mendekatkan diri kepada Tuhan, mereka pasrah terhadap penyakit yang diderita karena mereka menganggap bahwa penyakit ini merupakan cobaan dari Tuhan. 


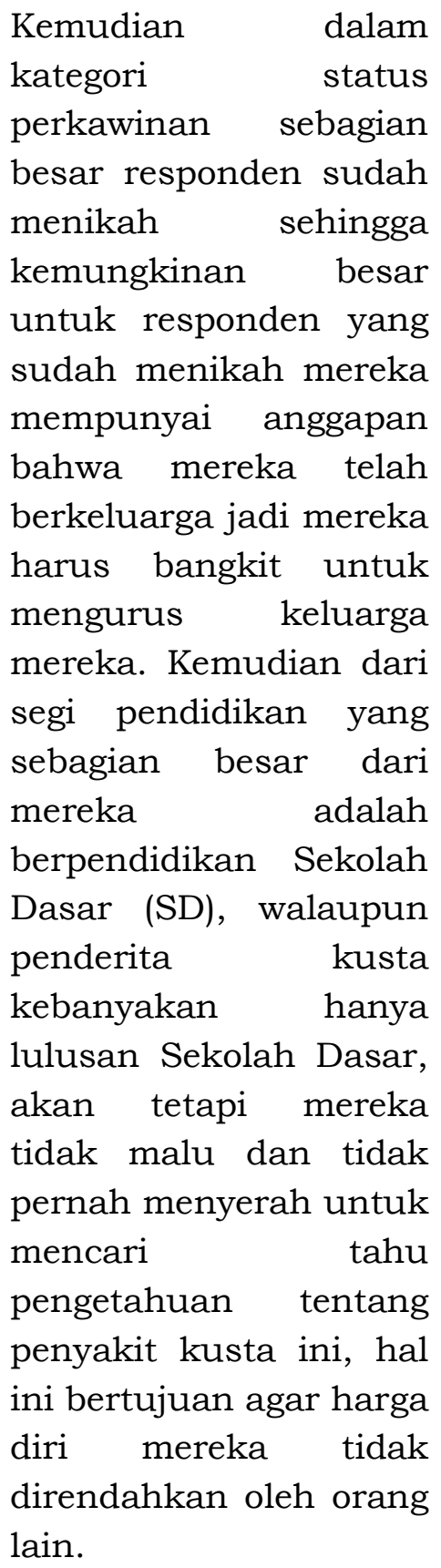

3. Pengaruh konseling terhadap peningkatan harga diri pasien kusta Konseling secara signifikan memberikan perubahan ke arah yang lebih baik terhadap harga diri, yang ditunjukkan dari data pre test dan post test yang kemudian diolah dengan menggunakan uji $\mathrm{T}$ pada pasien kusta. Setelah dilakukan konseling harga diri penderita kusta juga mengarah kearah yang lebih baik. Hal ini membuktikan bahwa antara konseling dapat mempengaruhi

seseorang yang secara langsung dapat meningkatkan harga diri responden menjadi kearah yang lebih baik. Harga diri adalah penilaian individu tentang nilai personal yang diperoleh dengan menganalisa seberapa baik perilaku seseorang 
Fahrur Rozi: Konseling Kusta

sesuai dengan ideal diri. Frekuensi pencapaian tujuan akan menghasilkan harga diri yang rendah atau harga diri yang tinggi. Jika individu sering gagal, maka cenderung harga diri rendah. Harga diri diperoleh dari diri sendiri dan orang lain. Aspek utama adalah dicintai dan menerima penghargaan dari orang lain (Stuart \& Sunndeen). Dalam penelitian ini, hasil pada saat pre test harga diri responden yang muncul adalah kurang dan sedang, namun setelah diberikan konseling tentang penyakit kusta harga diri responden berubah menjadi sedang dan tinggi.

Pesan atau message merupakan materi yang diberikan komunikator kepada pihak komunikan, dengan pengharapan agar apa yang diberikan itu dapat diterima oleh pihak komunikan secara baik. Mengenai masalah ini ada beberapa hal yang perlu pemikiran, yaitu sumber dan isi pesan yang disampaikan kepada komunikan perlu mendapatkan perhatian dengan sebaik-baiknya. Karena sumber pesan yang baik dalam arti mengacu pada permasalahan akan dapat memberikan suatu tanggapan tertentu terhadap materi yang dikemukakan

komunikator (konselor) suatu pesan atau materi yang sama, tetapi yang membawakan berbeda akan terdapat perbedaan dalam menerima materi tersebut. Disini nampak bahwa pihak komunikator ikut menentukan diterima 
tidaknya atau sampai sejauh mana kadar penerimaan materi dari pihak komunikan. Karena itu komunikator memegang peranan penting dalam rangka pengubahan atau pembentukan sikap secara langsung, dimana jika seorang komunikator dalam memberikan pendidikan kesehatan mempunyai teknik dalam cara membawakan atau menyajikan pesan dengan cara berbeda dan menguasai materi dengan baik, maka akan dapat menimbulkan

perbedaan dalam cara menanggapi atau penerimaan pesan yang diberikannya dan dapat pula mempengaruhi persepsi dan penerimaan responden (Mamppiare, 2008).

Komunikan inilah yang menjadi sasaran konselor untuk diberikan sesuatu pesan yang berwujud pandangan, pendapat, dan sebagainya, dengan upaya agar apa yang diberikan itu dapat diterima dengan baik oleh komunikan, sehingga akhirnya diharapkan akan dapat mengubah sikapnya. Tetapi selama berlangsungnya proses konseling terjadi pola pandang dan pendapat yang berbeda yang disebabkan karena penderita kusta mayoritas belum memahami benar mengenai kusta, baik cara penularan dan penanggulangannya secara benar, dan dari kurangnya informasi atau pemahaman mengenai kusta itulah maka, responden mempunyai pendapat atau pandangan yang berbeda mengenai kusta. Namun hal ini bisa diatasi dengan 
Fahrur Rozi: Konseling Kusta

$$
\begin{array}{lr}
\text { penyampaian } & \text { materi } \\
\text { yang baik dan jelas dari } \\
\text { konselor } & \text { sehingga } \\
\text { responden } & \text { yang } \\
\text { mayoritas } & \text { belum } \\
\text { memahami } & \text { benar } \\
\text { mengenai } & \text { kusta dan } \\
\text { kurangnya } & \text { informasi } \\
\text { tersebut } & \text { dapat } \\
\text { memahami } & \text { materi yang } \\
\text { diberikan dengan baik. }
\end{array}
$$

\section{Simpulan}

Efektifitas

konseling pada kasus kusta dalam peningkatan harga diri yang mengalami penurunan pada pasien yang menderita.

\section{Daftar Pustaka}

Arikunto, S. (2006).

Prosedur Penelitian

Suatu Pendekatan

Praktik. Jakarta :

Rineka Cipta.

Baradero, M. dkk.

(2006). Buku Saku

Konseling Dalam

keperawatan.

Jakarta : EGC.

Departemen Kesehatan

RI (2007). Buku
Pedoman Nasional

Pengendalian

Penyakit Kusta.

Jakarta : Dirjen

P2ML

http: / www.Globlal

leprosy

situation.com.

Diakses tanggal 09

Nopember 2011

Diakses Tanggal 15

Desember 2011

Kaosih, A. dkk. (2001).

Ilmu Penyakit Kulit

Dan Kelamin.

Jakarta : Fakultas

Kedokteran

Universitas

Indonesia.

Mansjoer, A. (2000).

Kapita Selekta

Kedoktreran.

Jakarta: Media

Asculapius.

Mappiare, A. (2008).

Pengantar

Konseling Dan

Psikoterapi. Jakarta

: PT Raja Grafindo

Persada. 
Fahrur Rozi: Konseling Kusta

Notoatmojo, S. (2007).

Promosi Kesehatan

(2011).

Bagian

dan Ilmu Perilaku.

Jakarta : Rineka

Cipta.

Rekam Medis.

Stuart. G. (1998). Buku Saku

Nursalam

(2008).

Konsep

\&

Penerapan

Metodologi

Penelitian

Ilmu

Keperawatan.

Jakarta : Salemba

Medika.

Potter \& Perry (2005).

Buku

Ajar

Fundamental

Keperawatan.

Jakarta : Penerbit

Buku Kedokteran

EGC.

Rahmat, H. (2003).

Kusta. Jakarta :

Balai Penerbit

Fakultas

Kedokteran

Universitas

Indonesia.

Rumah Sakit Kusta

Sumber Glagah

Pacet Mojokerto.

Keperawatan

Jiwa. Jakarta :

EGC.

Sujianto

(2002).

Konseling Dalam

Keperawatan.

Jakarta : Penerbit

Buku Kedokteran

EGC.

Sugiyono

(2010).

Statistika Untuk

Penelitian.

Bandung : CV

Alfabeta

Syaifuddin

(2002).

Psikologi Sosial :

Suatu Pengantar.

Edisi 9 Yogyakarta :

Andi Offset.

Tarwoto \& Wartonah

(2003). Kebutuhan

Dasar Manusia \&

Proses

Keperawatan.

Jakarta : Salemba

Medika. 
Fahrur Rozi: Konseling Kusta

Tyastuti, S. (2008).

Komunikasi dan

Konseling Dalam

Pelayanan

Kebidanan.

Yogyakarta :

Penerbit Fitramaya. 